\title{
Long-term results of treatment with bosentan in adult Eisenmenger's syndrome patients with Down's syndrome related to congenital heart disease
}

\author{
Roberto Crepaz ${ }^{1,3^{*}}$, Cristina Romeo ${ }^{1}$, Donato Montanaro ${ }^{1}$ and Stefano De Santis ${ }^{2}$
}

\begin{abstract}
Background: Patients with Down's syndrome and shunt lesions are at high risk of developing pulmonary arterial hypertension (PAH) earlier than patients without Down's syndrome. However, data on the efficacy of PAH-specific therapy in patients with Down's syndrome are limited. The aim of this retrospective analysis was to determine the long-term efficacy of the dual endothelin receptor antagonist, bosentan, in Eisenmenger's syndrome (ES) patients with Down's syndrome.

Methods: In this observational study adults with Down's syndrome with a confirmed diagnosis of ES (World Health Organization functional class III) and receiving bosentan therapy and were followed up long term. Clinical evaluation at baseline and follow-up visits included resting transcutaneous arterial oxygen saturation and laboratory assessments. Exercise capacity was evaluated using a 6-minute walk test where transcutaneous arterial oxygen saturation at peak exercise $\left(\mathrm{SpO}_{2}\right)$, 6-minute walk distance (6MWD) and Borg dyspnoea index were assessed. A full echocardiographic assessment was conducted at baseline and follow-up visits.

Results: Overall, seven adults (mean age $29.6 \pm 11.2$ years; $57 \%$ male) received bosentan at a starting dose of $62.5 \mathrm{mg}$ twice daily. This was increased to the target dose of $125 \mathrm{mg}$ twice daily 4 weeks later. All patients remained on bosentan until the end of the study. After a mean ( \pm standard deviation) duration of $52.2 \pm 3.9$ months (range: 46.0-55.5 months), 6MWD had increased from $199.6 \pm 69.1$ metres to $303.7 \pm 99.9$ metres $(P<0.05)$ and $\mathrm{SpO}_{2}$ at the end of the 6 -minute walk test had increased from $61.6 \pm 7.6 \%$ to $74.7 \pm 6.2 \%(P<0.05)$. Echocardiography demonstrated a significant change in acceleration time from $62.9 \pm 11.6 \mathrm{~m} / \mathrm{s}$ to $83.0 \pm 9.6 \mathrm{~m} / \mathrm{s}(P=0.0156)$, and acceleration time/ejection time ratio from the pulmonary flow from $0.24 \pm 0.04$ at baseline to $0.30 \pm 0.02(P=0.0156)$ at final follow-up.
\end{abstract}

Conclusions: Long-term treatment with bosentan significantly improved exercise capacity and oxygen saturation following exercise in adult ES patients with Down's syndrome. These data confirm that the presence of Down's syndrome does not affect the response to oral bosentan therapy.

Keywords: Bosentan, Eisenmenger's syndrome, Down's syndrome, Long-term

\footnotetext{
* Correspondence: robcrep@gmail.com

${ }^{1}$ Department of Cardiology and Pediatric Cardiology, Regional Hospital of Bolzano, Bolzano, Italy

${ }^{3}$ Cardiologia e Prove funzionali/Kardiologie und kardiologische

Funktionsproben, Ospedale Centrale di Bolzano/Krankenhaus Bozen,

Via/Straße Lorenz Böhler 5, 39100, Bolzano/Bozen, Italy

Full list of author information is available at the end of the article
} 


\section{Background}

Patients with congenital heart disease (CHD) with significant untreated left-to-right shunt lesions are at risk of developing pulmonary arterial hypertension (PAH). Eisenmenger's syndrome (ES), a clinical condition with an initial large systemic-to-pulmonary shunt that induces severe pulmonary vascular disease [1], represents the most advanced form of PAH-CHD and is characterised by reversed pulmonary-to-systemic (right-toleft) shunt and central cyanosis. The Euro Heart Survey on adult CHD (a retrospective cohort study with a 5year follow-up) reported PAH in 531 (28\%) patients [2], while a Dutch registry showed a PAH prevalence of $4.2 \%$ in 5970 adult patients with CHD [3]. In the latter registry, $58 \%$ of patients with a septal defect who developed PAH had ES.

Patients with Down's syndrome represent an important subgroup in the ES population as they are considered to be at risk of PAH earlier than patients without Down's syndrome and also have worse functional capacity [4]. This is probably due to different pathogenetic factors between patients with and without Down's syndrome [5]. Down's syndrome has been estimated to occur in $\approx 1.1 / 1000$ adults in the UK [6] and $\approx 1 / 732$ infants in the USA [7]. However, there is some evidence that prevalence varies between different racial and ethnic groups [8]. The association between Down's syndrome and CHD has been well established [9]. The prevalence of CHD in patients with Down's syndrome is $40-60 \%[10,11]$ and the types of malformation that are most commonly associated with trisomy 21 are the atrioventricular and ventricular septal defects (AVSD and VSD), which together account for $76 \%$ of all CHD seen in patients with Down's syndrome [12]. Although AVSD is frequently reported as the most common cardiac defect, there is some evidence that this varies according to sex and ethnicity [8,10-15].

Treatment options for ES patients are limited and the Bosentan Randomized Trial of Endothelin Antagonist Therapy-5 (BREATHE-5) study, which demonstrated the efficacy and tolerability of the endothelin receptor antagonist, bosentan, is the only placebo-controlled study in this population to date [16]. Data in patients with Down's syndrome are even more limited, with the only evidence of the efficacy of PAH-specific therapies in this population being from small, or single-centre studies [17-22].

The aim of the present study was to evaluate the longterm efficacy of bosentan in adult ES patients with Down's syndrome.

\section{Methods}

This was a retrospective analysis of data collected from consecutive adult ES patients with Down's syndrome (mild cognitive impairment verified by the Wechsler Adult Intelligence Scale - Revised [23]) treated with bosentan at our centre. Permission to collect data prospectively was obtained from the parents or the legal tutor prior to entering the study. Adults with a diagnosis of ES confirmed by right heart catheterization, in World Health Organization (WHO) functional class III between May 2007 and April 2008 were included. The final follow-up visits took place between January and February 2012.

Clinical evaluation at baseline included: medical history, WHO functional class, resting transcutaneous arterial oxygen saturation $\left(\mathrm{SaO}_{2}\right)$ for 30 minutes and liver enzymes (alanine aminotransferase [ALT], aspartate aminotransferase $[\mathrm{AST}])$. Exercise capacity was evaluated using a 6-minute walk test (6MWT) where the following variables were assessed: rest and peak exercise transcutaneous oxygen saturation $\left(\mathrm{SpO}_{2}\right)$, heart rate, systemic blood pressure, 6-minute walk distance (6MWD) and Borg dyspnoea index. Several days prior to the 6MWT patients were educated about the 6MWT. The test was performed under the same environmental conditions and at approximately the same time of the day ( \pm 1 hour) in all patients and physicians observed the patients' attention and approach to the 6MWT.

A complete Doppler echocardiography (echo) study was conducted in each patient according to current European guidelines [24]. The following variables were assessed: right ventricular (RV) systolic pressure from tricuspid regurgitation (TR) jets, maximal velocity from pulmonary regurgitation jets, acceleration/ejection time ratio (AcT/ ET) from the pulmonary flow, direction and maximal velocity across the VSD.

Bosentan was administered at a starting dose of $62.5 \mathrm{mg}$ twice daily immediately after the baseline assessment. The dose was increased to the target dose of $125 \mathrm{mg}$ twice daily 4 weeks later. Follow-up assessments were conducted in all patients at Months 3, 6, 9 and 12 of bosentan therapy and every 6 months, thereafter. Assessments included measurement of $\mathrm{SpO}_{2}$, blood tests, 6MWT and Doppler echo examination.

\section{Statistical analysis}

Continuous variables are presented as means with standard deviations and ranges, categorical data are presented as counts and percentages. Statistical analyses were performed using the Wilcoxon signed-rank test. Variables were analysed at baseline and at sequential follow-up visits. A $\mathrm{p}$ value $<0.05$ was considered as the level of significance.

\section{Results}

In total, seven adults (four males, three females) with Down's syndrome and ES were included. Their mean age was $29.6 \pm 11.2$ years, all patients were in WHO functional class III and had a VSD (two with associated mitral valve regurgitation). None of the patients had received previous PAH-specific therapy. Oxygen therapy was required 


\section{Table 1 Effect of bosentan on blood pressure, exercise capacity and blood oxygen saturation}

\begin{tabular}{|c|c|c|c|c|c|c|c|c|}
\hline $\begin{array}{l}\text { Parameter, mean } \pm S D \\
\text { ( } p \text { value) }\end{array}$ & Baseline & Month 3 & Month 6 & Month $9^{b}$ & Month 12 & Month 18 & Month 24 & Final follow-up ${ }^{a}$ \\
\hline$\overline{\mathrm{SBP}}(\mathrm{mmHg})$ & $125.7 \pm 14.0$ & $105.0 \pm 11.8^{\mathrm{b}}(0.063)$ & $111.7 \pm 9.8^{b}(0.125)$ & $111.7 \pm 5.2^{b}(0.094)$ & $114.3 \pm 13.7(0.250)$ & $113.7 \pm 9.6(0.188)$ & $106.4 \pm 7.5(0.063)$ & $108.6 \pm 9.0(0.094)$ \\
\hline $\mathrm{DBP}(\mathrm{mmHg})$ & $80.0 \pm 5.8$ & $74.2 \pm 8.6^{\mathrm{b}}(0.125)$ & $79.2 \pm 8.0^{b}(1.000)$ & $73.3 \pm 11.7^{\mathrm{b}}(0.281)$ & $69.3 \pm 8.4(0.031)$ & $73.6 \pm 8.5(0.250)$ & $68.9 \pm 7.8(0.063)$ & $68.6 \pm 4.8(0.031)$ \\
\hline $6 \mathrm{MWD}(\mathrm{m})$ & $199.6 \pm 69.1$ & $291.7 \pm 73.1^{\mathrm{b}}(0.063)$ & $260.7 \pm 60.2^{b}(0.063)$ & $292.3 \pm 112.7^{\mathrm{b}}(0.031)$ & $301.6 \pm 88.7(0.016)$ & $317.4 \pm 105.8(0.016)$ & $291.9 \pm 115.4(0.016)$ & $303.7 \pm 99.9(0.016)$ \\
\hline $\mathrm{SaO}_{2}(\%)$ at rest & $81.7 \pm 6.6$ & $87.2 \pm 5.6^{\mathrm{b}}(0.063)$ & $88.4 \pm 2.7(0.031)$ & $89.3 \pm 2.5^{\mathrm{b}}(0.031)$ & $89.0 \pm 2.5(0.016)$ & $87.9 \pm 4.5(0.109)$ & $89.3 \pm 1.8(0.031)$ & $88.3 \pm 3.2(0.016)$ \\
\hline $\mathrm{SpO}_{2}(\%)$ before $6 \mathrm{MWT}$ & $81.0 \pm 6.6$ & $87.0 \pm 6.4^{b}(0.094)$ & $87.2 \pm 3.8^{b} \quad(0.031)$ & $89.3 \pm 1.0^{b}(0.031)$ & $88.7 \pm 3.1(0.031)$ & $88.6 \pm 5.3(0.047)$ & $89.9 \pm 1.8(0.016)$ & $88.0 \pm 3.3(0.016)$ \\
\hline $\mathrm{SpO}_{2}(\%)$ at end of $6 \mathrm{MWT}$ & $61.6 \pm 7.6$ & $68.2 \pm 9.3^{b}(0.250)$ & $67.7 \pm 3.0^{\mathrm{b}}(0.063)$ & $72.5 \pm 6.2^{b}(0.031)$ & $70.6 \pm 10.1(0.078)$ & $71.0 \pm 7.5(0.016)$ & $74.3 \pm 5.4(0.016)$ & $74.7 \pm 6.2(0.016)$ \\
\hline Borg dyspnoea index & $3.6 \pm 1.4$ & $2.3 \pm 1.2^{b}(0.063)$ & $2.8 \pm 1.5^{\mathrm{C}}(0.250)$ & $3.2 \pm 1.2^{b}(1.000)$ & $2.1 \pm 1.2(0.016)$ & $2.9 \pm 1.8(0.313)$ & $3.7 \pm 2.9(1.000)$ & $2.4 \pm 1.1(0.250)$ \\
\hline
\end{tabular}

SBP: systolic blood pressure; DBP: diastolic blood pressure; $6 \mathrm{MWT}$ : 6-minute walk test; $\mathrm{SaO}_{2}$ : transcutaneous arterial oxygen saturation; $\mathrm{SpO}_{2}$ : peak exercise transcutaneous arterial oxygen saturation.

aWilcoxon signed-rank test (two-sided) on change from baseline statistically significant $(\mathrm{p}<0.05)$.

$\mathrm{b}_{\mathrm{n}}=6$ due to missing data.

$c_{n}=6$ due to missing data.
$c_{n}=5$ due to missing data. 

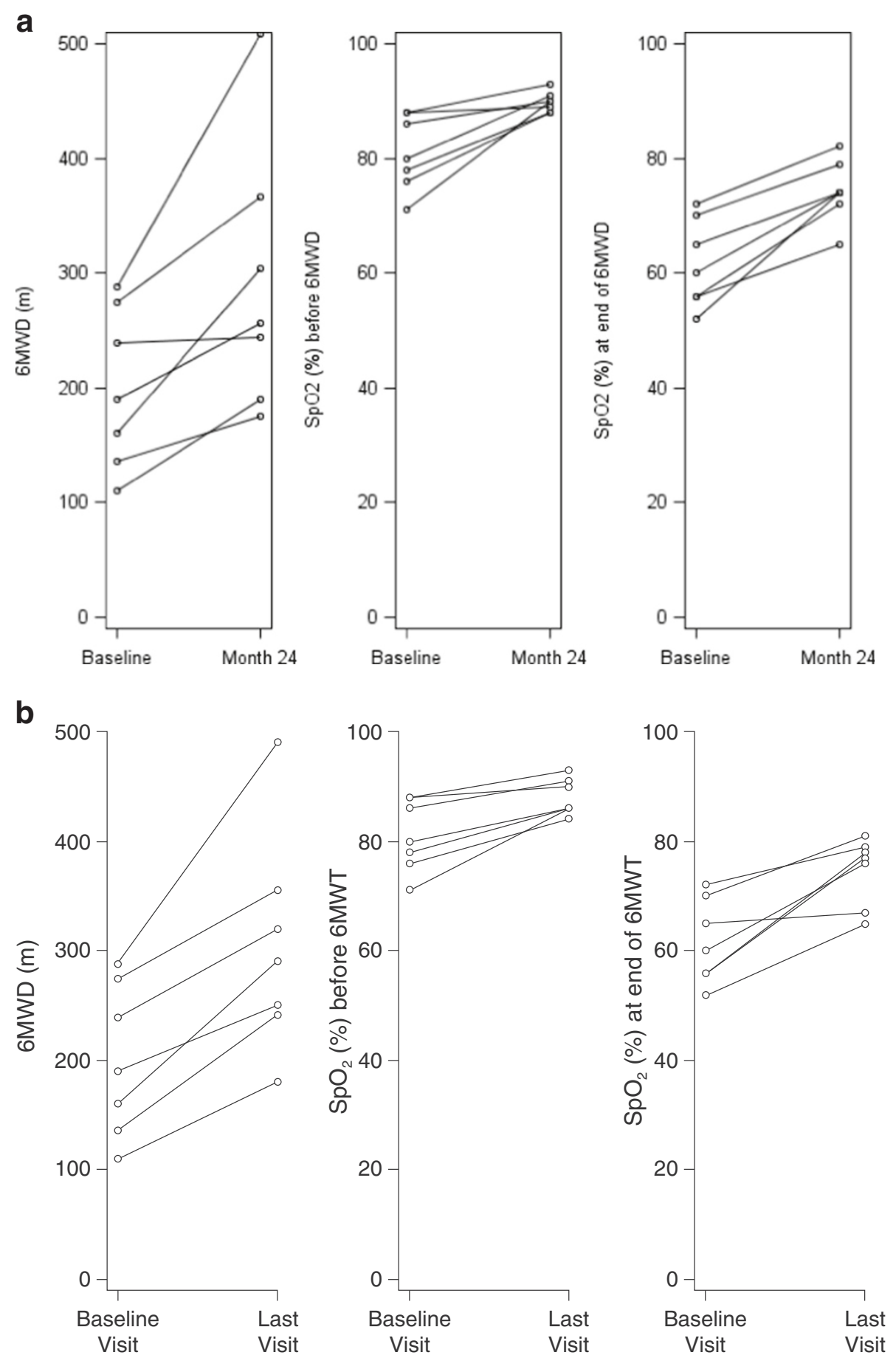

Figure 1 6-minute walk distance (6MWD), peak exercise transcutaneous arterial oxygen saturation $\left(\mathrm{SpO}_{2}\right)$ before and at the end of the 6-minute walk test at baseline and a. Month 24 and b. Last visit.

for 10 hours/day by two patients. Concomitant therapy was required by six patients (thyroid hormones $[n=6]$, allopurinol $[\mathrm{n}=3]$, ticlopidine $[\mathrm{n}=1]$ ). Baseline $\mathrm{SaO}_{2}$ at rest was $81.7 \pm 6.6 \%$ (range $71-88 \%$ ).
Patients were followed up for a mean period of $52.2 \pm$ 3.9 months (range 46.0-55.5 months). All patients remained on bosentan monotherapy until the end of the study. 
Table 2 Effect of treatment with bosentan on echocardiographic parameters

\begin{tabular}{llll}
\hline Parameter & Baseline & Final follow-up & $\boldsymbol{P}$ value $^{\mathbf{a}}$ \\
\hline RVSP from TR $(\mathrm{mmHg})(\mathrm{n}=4)$ & $94.0 \pm 13.4$ & $85.5 \pm 7.6$ & 0.3750 \\
Peak velocity of PR $(\mathrm{m} / \mathrm{s})(\mathrm{n}=2)$ & $4.00 \pm 0.14$ & $4.05 \pm 0.07$ & 1.0000 \\
ACT $(\mathrm{m} / \mathrm{s})$ & $62.9 \pm 11.6$ & $83.0 \pm 9.6$ & 0.0156 \\
AcT/ET & $0.24 \pm 0.04$ & $0.30 \pm 0.02$ & 0.0156 \\
\hline
\end{tabular}

RVSP: right ventricular systolic pressure; TR: tricuspid regurgitation; PR: pulmonary regurgitation; AcT: acceleration time; AcT/ET: acceleration/ejection time ratio; ${ }^{a}$ Wilcoxon signed-rank test.

\section{Clinical assessment}

In comparison with the baseline evaluation, at the final follow-up assessment, there was an improvement to WHO functional class II in one patient. Mean $\mathrm{SaO}_{2}$ at rest increased from $81.7 \pm 6.6 \%$ (range $71-88 \%$ ) at baseline to $89.0 \pm 3 \%$ (range $87-92 \%)(P<0.02)$ at Month 24 and $88.3 \pm 3.2 \%$ (range $84-93 \%$ ) at the final follow-up assessment $(\mathrm{p}<0.05)$. AST and ALT levels increased slightly in one patient, but remained lower than twice the upper limit of normal.

The mean 6MWD increased from 199.6 \pm 69.1 metres at the baseline assessment to $291.9 \pm 115$ metres at Month $24(P=0.016)$ and $303.7 \pm 99.9$ metres at the final followup assessment $(P=0.016)$. The mean $\mathrm{SpO}_{2}$ at the end of the $6 \mathrm{MWT}$ was $61.6 \pm 7.6 \%$ at the baseline assessment, $74.3 \pm 5.4 \%$ at the Month 24 assessment $(P=0.016)$ and $74.7 \pm 6.2 \%$ at the final follow-up assessments $(\mathrm{p}=0.016)$. Borg dyspnoea index was $3.6 \pm 1.4$ at baseline and $2.4 \pm 1.1$ at the final follow-up assessment (not significant). Diastolic blood pressure decreased from $80.0 \pm 5.8 \mathrm{mmHg}$ (range: $70-90 \mathrm{mmHg}$ ) at the baseline assessment to $68.6 \pm$ $4.8 \mathrm{mmHg}$ (range: $60-75 \mathrm{mmHg}$ ) at the final assessment (Table 1, and Figure 1).

\section{Doppler echo assessment}

Baseline echo parameters are shown in Table 2. At final follow-up there was a significant change in AcT $(\mathrm{p}<0.0156)$ and AcT/ET ratio $(\mathrm{p}<0.0156)$ from the pulmonary flow. RV and left ventricular systolic functions remained stable during follow-up (Table 2).

\section{Discussion}

In this long-term analysis, treatment of adult ES patients with Down's syndrome with bosentan for a mean period of more than 4 years resulted in significant initial improvements in $\mathrm{SaO}_{2}$ at rest and 6MWD that were sustained during follow-up. Treatment options for patients with ES are limited, with the BREATHE-5 study being the only placebo-controlled study in this population [16]. It demonstrated that bosentan significantly reduced pulmonary vascular resistance index and mean pulmonary arterial pressure and significantly improved 6MWD in ES patients in WHO functional class III. Safety (change from baseline in $\mathrm{SpO}_{2}$ ) was the primary endpoint in the BREATHE-5 study and the authors demonstrated that bosentan did not worsen oxygen saturation. Data from a number of studies, including the current study, have since confirmed these benefits in the longer term in patients with PAH-CHD and specifically in patients with ES [19,21,25-28]. In addition, PAH-specific therapy has been shown to significantly lower the all-cause mortality rate in a large population of ES patients, providing strong conceptual support for treatment of all ES patients with PAH-specific therapy [29].

Patients with Down's syndrome are at risk of developing PAH earlier than patients without Down's syndrome and have worse functional capacity [1]. Both these factors are associated with poor long-term outcome $[4,5,29-31]$. There are no randomized controlled trials in this subpopulation of PAH-CHD patients. The results of our long-term analysis support data from previous open-label studies, which have demonstrated the efficacy of bosentan in ES patients with Down's syndrome [19-21], and suggest that up to 4 years' treatment can be beneficial in these patients. A previous study has shown that there was no significant difference in mortality between ES patients with and without Down's syndrome after 4 years of bosentan treatment [21]. Similarly, no differences in the efficacy of bosentan between PAHCHD patients with and without Down's syndrome in a 12-month study have been reported, with both groups showing significant improvements in 6MWD, WHO functional class and haemodynamics [20].

The validity of the 6MWT in patients with Down's syndrome has been questioned as it has been reported that level of intellectual disability is an independent factor for 6MWD [32]. Vis and coworkers showed that there was a significant difference in mean 6MWD between the group with a mild/moderate level of intellectual disability $(318 \pm$ 92 metres) and the group with a severe/profound level of intellectual disability (195 \pm 84 metres). In our study, patients had a low level of intellectual disability; however, $6 \mathrm{MWD}$ was in the range seen in patients with severe intellectual disability in the Vis study. Importantly in the current study, patients achieved a significant increase in 6MWD with long-term bosentan therapy. These findings are similar to those from a recently published series of patients which demonstrated that 6MWD increased in patients with Down's syndrome during the first 12 months of bosentan therapy - achieving early significance - and this improvement from baseline was maintained during a further 24 months of therapy [18]. Although it has been shown that there is no discrepancy between improvement in 6MWD and haemodynamic parameters in patients with Down's syndrome [20], it is clear from the contrasting results from published small studies that we still need to understand more about use of the 6MWT in this 
population. Consequently, although there is some debate about the most appropriate assessment in this patient population, evidence of bosentan efficacy has been demonstrated. Based on our experience, we believe that patients' compliance - in the presence of mild intellectual disability - is sufficient to guarantee a reliable result as confirmed by the assessment of objective parameters.

In the present study we did not perform an invasive evaluation such as right heart catheterization during followup visits. However, several studies report a high correlation (0.57 to 0.93 ) between echocardiographic and haemodynamic measurements of pulmonary arterial systolic pressure and, therefore, the echocardiographic assessment used in the current analysis provides valid information [33-35]. Baseline values of TR velocity and pulmonary arterial systolic pressure in the patients included in the current study were higher than those associated with the presence of pulmonary hypertension as specified in the current guidelines [24]. Additional variables to confirm the presence of pulmonary hypertension were also included in accordance with the guidelines (i.e. increased pulmonary valve regurgitation velocity, shortened acceleration time of RV ejection into the pulmonary artery, increased dimensions of the right heart chambers, abnormal shape and function of the interventricular septum and increased right ventricular wall thickness and pericardial effusion were demonstrated).

WHO functional class remained stable in the majority of patients during treatment, with an improvement in functional class being achieved by one patient. In the BREATHE- 5 study, pulmonary vascular resistance index increased in the placebo arm during the 16-week study period, demonstrating the progressive nature of ES [16]. As a result, the maintenance of patients in WHO functional class III during prolonged bosentan therapy is encouraging.

The long-term results from this study provide confirmation of the significant improvement in exercise capacity and $\mathrm{SpO}_{2}$ in ES patients with Down's syndrome seen in previous studies $[17,20,21]$. Additionally, this improvement was quick and progressive (in the first 6 months) and was then stable for up to 48 months.

Our study has some limitations, specifically the small number of patients and the lack of a placebo-controlled group and that data are only confirmed by echocardiography and not by right heart catheterization. However, it represents, with few other studies, one of the largest series of ES patients with Down's syndrome treated with bosentan for an extended period. As a result the significant and stable increase in 6MWD and oxygen saturation are of clinical relevance.

\section{Conclusion}

Long-term treatment with bosentan in adult ES patients with Down's syndrome was well tolerated and significantly improved oxygen saturation and 6MWD. Our study confirms that the presence of Down's syndrome does not affect the response to oral bosentan therapy in adult ES patients.

\section{Abbreviations}

ACT/ET: Acceleration/ejection time ratio; ALT: Alanine aminotransferase; AST: Aspartate aminotransferase; AVSD: Atrioventricular septal defect; CHD: Congenital heart disease; echo: Echocardiography; ES: Eisenmenger's syndrome; PAH: Pulmonary arterial hypertension; RV: Right ventricle; $\mathrm{SaO}_{2}$ : Transcutaneous arterial oxygen saturation; $\mathrm{SpO}_{2}$ : Peak exercise transcutaneous arterial oxygen saturation; TR: Tricuspid regurgitation; VSD: Ventricular septal defect; WHO: World Health Organization; 6MWD: 6-minute walk distance; 6MWT: 6-minute walk test.

\section{Competing interests}

Roberto Crepaz, Cristina Romeo and Donato Montanaro disclose no potential conflicts of interest. Stefano De Santis is a full-time employee of Actelion Pharmaceuticals Italia Srl.

\section{Authors' contributions}

$\mathrm{RC}$ conceived the study, participated in its design and coordination. CR treated patients and performed evaluations. DM treated patients and performed evaluations. All authors contributed to the development of the manuscript and approved the final draft.

\section{Acknowledgments}

We are grateful and thankful to Jean-Christophe Lemarié for statistical analysis (Effi-Stat, Paris, France) and Elisa Dalmonte (Actelion employee) for reviewing the English manuscript. The editorial assistance of Liesje Quine (Elements Communications Ltd, Westerham, UK), funded by Actelion Pharmaceuticals, Allschwil, Switzerland, was also appreciated.

\section{Author details}

'Department of Cardiology and Pediatric Cardiology, Regional Hospital of Bolzano, Bolzano, Italy. ${ }^{2}$ Medical Department, Actelion Pharmaceuticals Italia Srl, Imola, Italy. ${ }^{3}$ Cardiologia e Prove funzionali/Kardiologie und kardiologische Funktionsproben, Ospedale Centrale di Bolzano/Krankenhaus Bozen, Via/Straße Lorenz Böhler 5, 39100, Bolzano/Bozen, Italy.

Received: 14 March 2013 Accepted: 4 September 2013

Published: 18 September 2013

\section{References}

1. Galie N, Manes A, Palazzini M, Negro L, Marinelli A, Gambetti S, Mariucci E, Donti A, Branzi A, Picchio FM: Management of pulmonary arterial hypertension associated with congenital systemic-to-pulmonary shunts and Eisenmenger's syndrome. Drugs 2008, 68:1049-1066.

2. Engelfriet PM, Duffels MG, Möller T, Boersma E, Tijssen JG, Thaulow E, Gatzoulis MA, Mulder BJ: Pulmonary arterial hypertension in adults born with a heart septal defect: the Euro Heart Survey on adult congenital heart disease. Heart 2007, 93:682-687.

3. Duffels MG, Engelfriet PM, Berger RM, van Loon RL, Hoendermis E, Vriend $J W$, van der Velde ET, Bresser P, Mulder BJ: Pulmonary arterial hypertension in congenital heart disease: an epidemiologic perspective from a Dutch registry. Int J Cardiol 2007, 120:198-204.

4. Van de Bruaene A, Delcroix M, Pasquet A, De Backer J, De Pauw M, Naeije R, Vachiéry JL, Paelinck B, Morissens M, Budts W: The Belgian Eisenmenger syndrome registry: implications for treatment strategies? Acta Cardiol 2009, 64:447-453.

5. Suzuki K, Yamaki S, Mimori S, Murakami Y, Mori K, Takahashi Y, Kikuchi T: Pulmonary vascular disease in Down's syndrome with complete atrioventricular septal defect. Am J Cardiol 2000, 86:434-437.

6. Morris JK, Alberman E: Trends in Down's syndrome live births and antenatal diagnoses in England and Wales from 1989 to 2008: analysis of data from the National Down Syndrome Cytogenetic Register. BMJ 2009, 339:b3794

7. Mulder BJM: Changing demographics of pulmonary arterial hypertension in congenital heart disease. Eur Respir Rev 2010, 19:308-313. 
8. Sherman SL, Allen EG, Bean LH, Freeman SB: Epidemiology of Down syndrome. Ment Retard Dev Disabil Res Rev 2007, 13:221-227.

9. Evans PR: Cardiac anomalies in mongolism. Br Heart J 1950, 12:258-262.

10. Freeman SB, Bean $L H$, Allen EG, Tinker SW, Locke AE, Druschel C, Hobbs CA, Romitti PA, Royle MH, Torfs CP, Dooley KJ, Sherman SL: Ethnicity, sex, and the incidence of congenital heart defects: a report from the National Down Syndrome Project. Genet Med 2008, 10:173-180.

11. Paladini D, Tartaglione A, Agangi A, Teodoro A, Forleo F, Borghese A, Martinelli P: The association between congenital heart disease and Down syndrome in prenatal life. Ultrasound Obstet Gynecol 2000, 15:104-108.

12. Ferencz C, Neill CA, Boughman JA: Congenital cardiovascular malformations with chromosome abnormalities: an epidemiologic study. J Pediatr 1989, 144:79-86

13. Chéhab G, El-Rassi I, Abdo A, Fakhoury H, Chokor I, Haddad W, Saliba Z: Atrioventricular septal defect characteristics in infants with and without Down's syndrome: a Lebanese study. J Med Leban 2010, 58:3-7.

14. Placidi S, Digilio MC, Marino B: Types of cardiac defects in children with Down's syndrome. Cardiol Young 2006, 16:198-199.

15. Elmagrpy Z, Rayani A, Shah A, Habas E, Aburawi EH: Down syndrome and congenital heart disease: why the regional difference as observed in the Libyan experience? Cardiovasc J Afr 2011, 22:306-309.

16. Galiè N, Beghetti M, Gatzoulis MA, Granton J, Berger RM, Lauer A, Chiossi E, Landzberg M, Bosentan randomized trial of endothelin antagonist therapy-5 (BREATHE-5) investigators: Bosentan therapy in patients with Eisenmenger Syndrome: a multicenter, double-blind, randomized, placebo-controlled study. Circulation 2006, 114:48-54.

17. Duffels MGJ, Vis JC, van Loon RLE, Berger RM, Hoendermis ES, van Dijk AP, Bouma BJ, Mulder BJ: Down patients with Eisenmenger syndrome: is bosentan treatment an option? Int J Cardiol 2009, 134:378-383.

18. Serino G, Guazzi M, Micheletti A, Lombardi C, Danesi R, Negura D, Carminati M, Chessa M: Effect of bosentan on exercise capacity and clinical worsening in patients with dual down and eisenmenger syndrome. Clin Med Insights Cardiol 2013, 7:29-34.

19. Monfredi O, Griffiths L, Clarke B, Mahadevan VS: Efficacy and safety of bosentan for pulmonary arterial hypertension in adults with congenital heart disease. Am J Cardiol 2011, 108:1483-1488.

20. D'Alto M, Romeo E, Argiento P, D'Andrea A, Sarubbi B, Correra A, Scognamiglio G, Papa S, Bossone E, Calabrò R, Vizza CD, Russo MG: Therapy for pulmonary arterial hypertension due to congenital heart disease and Down's syndrome. Int J Cardiol 2013, 164:64-69.

21. Vis JC, Duffels MG, Mulder P, de Bruin-Bon RH, Bouma BJ, Berger RM, Hoendermis ES, van Dijk AP, Mulder BJ: Prolonged beneficial effect of bosentan treatment and 4-year survival rates in adult patients with pulmonary arterial hypertension associated with congenital heart disease. Int J Cardiol 2013, 164:64-69.

22. Kermeen FD, Franks C, O'Brien K, Seale H, Hall K, McNeil K, Radford D: Endothelin receptor antagonists are an effective long term treatment option in pulmonary arterial hypertension associated with congenital heart disease with or without trisomy 21. Heart Lung Circ 2010, 19:595-600.

23. Wechsler D: The Measurement and Appraisal of Adult Intelligence. 4th edition. Baltimore, MD, USA: Williams \& Wilkins Co; 1958:297. doi: 10.1037/11167-000.

24. Galiè N, Hoeper MM, Humbert M, Torbicki A, Vachiery JL, Barbera JA, Beghetti M, Corris P, Gaine S, Gibbs JS, Gomez-Sanchez MA, Jondeau G, Klepetko W, Opitz C, Peacock A, Rubin L, Zellweger M, Simonneau G, Vahanian A, Auricchio A, Bax J, Ceconi C, Dean V, Filippatos G, FunckBrentano C, Hobbs R, Kearney P, McDonagh T, McGregor K, Popescu BA, et al: Guidelines for the diagnosis and treatment of pulmonary hypertension: the task force for the diagnosis and treatment of pulmonary hypertension of the European Society of Cardiology (ESC) and the European Respiratory Society (ERS), endorsed by the International Society of Heart and Lung Transplantation (ISHLT). Eur Heart J 2009, 30:2493-2537.

25. D'Alto M, Vizza CD, Romeo E, Badagliacca R, Santoro G, Poscia R, Sarubbi B, Mancone M, Argiento P, Ferrante F, Russo MG, Fedele F, Calabrò R: Long term effects of bosentan treatment in adult patients with pulmonary arterial hypertension related to congenital heart disease (Eisenmenger physiology): safety, tolerability, clinical, and haemodynamic effect. Heart 2007, 93:621-625.

26. Diller GP, Dimopoulos K, Kaya MG, Harries C, Uebing A, Li W, Koltsida E, Gibbs JS, Gatzoulis MA: Long-term safety, tolerability and efficacy of bosentan in adults with pulmonary arterial hypertension associated with congenital heart disease. Heart 2007, 93:974-976.

27. Díaz-Caraballo E, González-García AE, Reñones M, Sánchez-Recalde A García-Río F, Oliver-Ruiz JM: Long-term bosentan treatment of complex congenital heart disease and Eisenmenger's syndrome. Rev Esp Cardiol 2009, 62:1046-1049.

28. Kaya MG, Lam YY, Erer B, Ayhan S, Vatankulu MA, Nurkalem Z, Meric M, Eren $M$, Eryol NK: Long-term effect of bosentan therapy on cardiac function and symptomatic benefits in adult patients with Eisenmenger syndrome. J Card Fail 2012, 18:379-384.

29. Dimopoulos K, Inuzuka R, Goletto S, Giannakoulas G, Swan L, Wort SJ, Gatzoulis MA: Improved survival among patients with Eisenmenger syndrome receiving advanced therapy for pulmonary arterial hypertension. Circulation 2010, 121:20-25.

30. Chi TP, Krovetz JL: The pulmonary vascular bed in children with Down syndrome. J Pediatr 1975, 86:533-538.

31. Yamaki S, Yasui H, Kado H, Yonenaga K, Nakamura Y, Kikuchi T, Ajiki $H_{\text {, }}$ Tsunemoto M, Mohri H: Pulmonary vascular disease and operative indications in complete atrioventricular canal defect in early infancy. J Thorac Cardiovasc Surg 1993, 106:398-405.

32. Vis JC, Thoonsen H, Duffels MG, de Bruin-Bon RA, Huisman SA, van Dijk AP, Hoendermis ES, Berger RM, Bouma BJ, Mulder BJ: Six-minute walk test in patients with Down syndrome: validity and reproducibility. Arch Phys Med Rehabil 2009, 90:1423-1427.

33. Bossone E, Avelar E, Bach DS, Gillespie B, Rubenfire M, Armstrong WF: Diagnostic value of resting tricuspid regurgitation velocity and right ventricular ejection flow parameters for the detection of exerciseinduced pulmonary arterial hypertension. Int J Card Imaging 2000, 16:429-436.

34. Denton C, Cailes J, Phillips G, Wells A, Black C, Du Bois R: Comparison of Doppler echocardiography and right heart catheterization to assess pulmonary hypertension in systemic sclerosis. Br J Rheumatol 1997, 36:239-243.

35. Penning S, Robinson K, Major C, Garite T: A comparison of echocardiography and pulmonary artery catheterization for evaluation of pulmonary artery pressures in pregnant patients with suspected pulmonary hypertension. Am J Obstet Gynecol 2001, 184:1568-1570.

doi:10.1186/1471-2261-13-74

Cite this article as: Crepaz et al:: Long-term results of treatment with bosentan in adult Eisenmenger's syndrome patients with Down's syndrome related to congenital heart disease. BMC Cardiovascular Disorders 2013 13:74

\section{Submit your next manuscript to BioMed Central and take full advantage of:}

- Convenient online submission

- Thorough peer review

- No space constraints or color figure charges

- Immediate publication on acceptance

- Inclusion in PubMed, CAS, Scopus and Google Scholar

- Research which is freely available for redistribution 